\title{
Alopecia Areata: Good Response to Treatment with Fractional Laser in 5 Cases
}

\author{
Nerea Landa Gundin, Marta Mendieta Eckert ${ }^{*}$ and Raquel Lambea Crespo
}

Dermitek Clinic, Paseo Uribitarte 11-12 Bajo, 48001 Bilbao, Spain

*Corresponding author: Marta Mendieta Eckert, Dermitek Clinic, Paseo Uribitarte 11-12 Bajo, 48001 Bilbao, Spain, Tel: +34 652749980; Fax: +34 944010111; E-mail: mmendieta@dermitek.com

Received date: March 20, 2016; Accepted date: April 05, 2016; Published date: April 09, 2016

Copyright: @2016 Landa N, et al. This is an open-access article distributed under the terms of the Creative Commons Attribution License, which permits unrestricted use, distribution, and reproduction in any medium, provided the original author and source are credited.

\section{Introduction}

Alopecia areata is a chronic inflammatory disease that results in a non-scarring hair loss. It occurs as an acute and complete loss of hair in a single or several areas, classically with morphology of circles and in the course of a few weeks. It can affect areas of the scalp, beard, eyebrows, eyelashes or be generalized being called alopecia universalis. The incidence appears to be similar in different countries. It affects both sexes equally and all ages [1,2]. Its cause is unknown and nowadays is classified as an autoimmune disease with genetic predisposition, as there is some family tendency [1]. A known trigger is the sustained stress, in which case appears after months of the episode [2]. Its prognosis is variable. Among the $34-50 \%$ of patients with a small number of circumscribed patches and short course can have spontaneous hair regrowth within 1 to several years [3-5]. Other patients will progress to total loss of hair and have a poor prognosis, being the alopecia permanent [4]. There are several factors of poor prognosis: severity at presentation, onset during childhood, nail abnormalities and ophiasis [1-5]. Since it is not possible to predict the course of the disease and it may have a serious psychological effect, an active treatment is proposed in many patients. There are several treatments with different results that can induce hair growth [1]. The most used and useful ones are topical and intralesional corticosteroids. Different topics such corticosteroids, diphencyprone irritant, minoxidil, calcineurin inhibitors and derivatives of prostaglandins are also used. Other options are: photochemotherapy (psoralen plus ultraviolet A), oral ciclosporin and oral methotrexate with less evidence $[1,2]$. In the last years it has also been treated with lights and some types of laser $[5,6]$.

\section{Case Reports}

We present five patients with diagnosis of patchy alopecia areata localized in the scalp, one with a plaque in the eyebrow and other in the beard. The diagnosis of alopecia areata was performed clinically. Three were women and two men with ages 44 to 59 years (mean age 48.8 years). The time of diagnosis of alopecia areata ranged from 1 month to 19 years (median 2 years). Three patients had received treatment with intralesional corticosteroids or topical minoxidil before for other plaques of alopecia. The other two had never had any episode of alopecia areata before and had not received any treatment. The time of progression of the new episode ranged from 1 to 9 months. In three cases the emotional stress was identified as a trigger, while in the rest there was no apparent trigger. Patients have no known endocrine disorder.

All of them were treated with non-ablative $1550 \mathrm{~nm}$ erbium glass fractional laser (Fraxel囚, Solta Medical). 2 to 3 sessions were performed, with an interval of 3-6 weeks and the following parameters: fluences ranging from $30-45 \mathrm{~mJ} / \mathrm{cm}^{2}, 6-8$ density and $8-10$ passes. The treatment was performed without local anesthesia with an air cooling system. The results were evaluated by a dermatologist on a visual global improvement score scale: $0-25 \%$ improvement, $26-50 \%, 51-75 \%$ and greater than $75 \%$. The onset of response was seen early at 2 weeks (Figures 1 and 2). All patients obtained a fully or almost fully regrowth at 3 months (Figures 3 and 4). No recurrence of the same plaques was observed in a follow up of 2 to 4 years but new plaques were developed in the patient with alopecia areata of 19 years of evolution. In all cases the regrowth of hair appeared with terminal hair and in its original color.

No side effects were reported except pain during treatment that was well tolerated.

\section{Discussion}

Treatment of alopecia areata is based in that hair follicles are preserved so the potential for recovery of hair growth is maintained. The use of light systems to stimulate hair growth is known for years. Several types of wavelength of the electromagnetic spectrum (like UVA, UVB and infrared radiation) have been used with varying results and proposed with an evidence level of 3 [1,6-10]. Infrared radiation can be emitted in the form of simple light multidirectional not coherent type diodes, as laser rays unidirectional and coherent or even mixed forms on devices that include both types of light. These new sources of light called low level laser therapy (LLLT) are spreading to androgenetic alopecia as hats or helmets for home use [11]. A study with 34 resistant patches treated with a low-level invisible pulsed infrared diode laser $(904 \mathrm{~nm}$ ) showed regrowth of hair in $94 \%$ patches. Besides, in $75 \%$ of them the regrowth was as early as 1 week after the first session [10]. However, our experience with LLLT in alopecia areata is restricted to a case of eyebrow alopecia where we had no results after 12 sessions of red light $630 \mathrm{~nm}, 20-30 \mathrm{~mJ}, 23 \mathrm{~min} / \mathrm{session}$.

A Korean group of has published a case of alopecia areata that regrew after 1 session of fractional laser [12]. Afterwards other cases have been published and it has been proposed too as a treatment for female pattern hair loss [13]. Fractional light sources are lasers that emit radiation in micro fractional columns of light that penetrate the dermis and produce heat [13-15]. The epidermis receives minimal damage that is recovered in days, which is one of its greatest advantages. Besides, it cannot produce hair removal because it has no affinity for melanin. A fractional laser can penetrate 3-4 $\mathrm{mm}$ into the dermis, depositing thermal energy where the dermal papilla is, which is where the capillaries are surrounding the hair germ cells [16]. It has been suggested that fractional laser could act by inducing T-cell apoptosis, wounding increased blood flow and promoting telogen to anagen transitions $[12,13,15]$. Recently, a murine model study showed anagen induction related to $\mathrm{Wnt} / \beta$-catenin pathway after fractional 
Citation: Landa N, Mendieta M, Lambea R (2016) Alopecia Areata: Good Response to Treatment with Fractional Laser in 5 Cases. J Cosmo

Page 2 of 4

laser treatment, resulting in hair regrowth and proportion of anagen increased in histological examination [17].

\begin{tabular}{|c|c|c|c|c|c|c|c|c|c|c|}
\hline $\begin{array}{l}\text { S.N } \\
0\end{array}$ & Age & Trigger & $\begin{array}{l}\text { Previous } \\
\text { treatment }\end{array}$ & Location & Size & $\begin{array}{l}\text { Time to } \\
\text { progession }\end{array}$ & $\begin{array}{l}\text { Fraxel } \\
\text { parameters }\end{array}$ & $\begin{array}{l}\text { Number of } \\
\text { sessions }\end{array}$ & Response & Follow up \\
\hline \multirow[t]{3}{*}{1} & \multirow[t]{3}{*}{$44 \mathrm{M}$} & \multirow[t]{3}{*}{ Stress } & \multirow[t]{3}{*}{$\begin{array}{l}\text { II } \\
\text { corticosteroids }\end{array}$} & Eyebrow & Unknown & $1 \mathrm{~m}$ & $\begin{array}{l}40-45 \mathrm{~mJ} / 8,8-10 \\
\text { passes }\end{array}$ & \multirow[t]{3}{*}{3} & $51-75 \%$ at $1 \mathrm{~m}$ & \multirow[t]{3}{*}{4 years } \\
\hline & & & & Temporal & $40 \times 30 \mathrm{~mm}$ & $2 \mathrm{~m}$ & $\begin{array}{l}30-40 \mathrm{~mJ} / 6-8,8 \\
\text { passes }\end{array}$ & & $\begin{array}{l}51-75 \% \text { at } 1 \\
\mathrm{~m} ;>75 \% \text { at } 3 \\
\mathrm{~m}\end{array}$ & \\
\hline & & & & Occipital & $20 \times 20 \mathrm{~mm}$ & $2 \mathrm{~m}$ & $\begin{array}{l}30-40 \mathrm{~mJ} / 6-8,8 \\
\text { passes }\end{array}$ & & $\begin{array}{l}25-50 \% \text { at } 1 \\
\mathrm{~m} ;>75 \% \text { at } 3 \\
\text { months }\end{array}$ & \\
\hline 2 & $59 \mathrm{~F}$ & Unknown & $\begin{array}{l}\text { II } \\
\text { corticosteroids } \\
\text { minoxidil topical }\end{array}$ & Frontal & $50 \times 40 \mathrm{~mm}$ & $1 \mathrm{~m}$ & $\begin{array}{l}35 \mathrm{~mJ} / 8, \quad 8 \\
\text { passes }\end{array}$ & 2 & $>75 \%$ at $3 \mathrm{~m}$ & 2 years \\
\hline \multirow[t]{2}{*}{3} & \multirow[t]{2}{*}{$45 \mathrm{~F}$} & \multirow[t]{2}{*}{ Unknown } & \multirow[t]{2}{*}{$\begin{array}{l}\text { II } \\
\text { corticosteroids }\end{array}$} & $\begin{array}{l}\text { Fronto- } \\
\text { temporal }\end{array}$ & $70 \times 50 \mathrm{~mm}$ & \multirow[t]{2}{*}{$9 m$} & \multirow[t]{2}{*}{$\begin{array}{l}35-40 \mathrm{~mJ} / 8,8-10 \\
\text { passes }\end{array}$} & \multirow[t]{2}{*}{3} & \multirow[t]{2}{*}{$>75 \%$ at $2 \mathrm{~m}$} & \multirow[t]{2}{*}{2 years } \\
\hline & & & & Occipital & $20 \times 20 \mathrm{~mm}$ & & & & & \\
\hline \multirow[t]{2}{*}{4} & & & \multirow[t]{2}{*}{ None } & \multirow[t]{2}{*}{ Beard } & $20 \times 20 \mathrm{~mm}$ & \multirow[t]{2}{*}{$1 \mathrm{~m}$} & \multirow{2}{*}{$\begin{array}{l}40 \mathrm{~mJ} / 8, \quad 8 \\
\text { passes }\end{array}$} & \multirow[t]{2}{*}{3} & $51-75 \%$ at $1 \mathrm{~m}$ & \multirow[t]{2}{*}{3 years } \\
\hline & & & & & $70 \times 50 \mathrm{~mm}$ & & & & $>75 \%$ at $3 \mathrm{~m}$ & \\
\hline 5 & & & None & Occipital & $30 \times 30 \mathrm{~mm}$ & $1 \mathrm{~m}$ & $\begin{array}{l}40 \mathrm{~mJ} / 8,8 \\
\text { passes }\end{array}$ & 2 & $>75 \%$ at $2 \mathrm{~m}$ & 2 years \\
\hline
\end{tabular}

Table 1: Description of the 5 cases, parameters and responses.

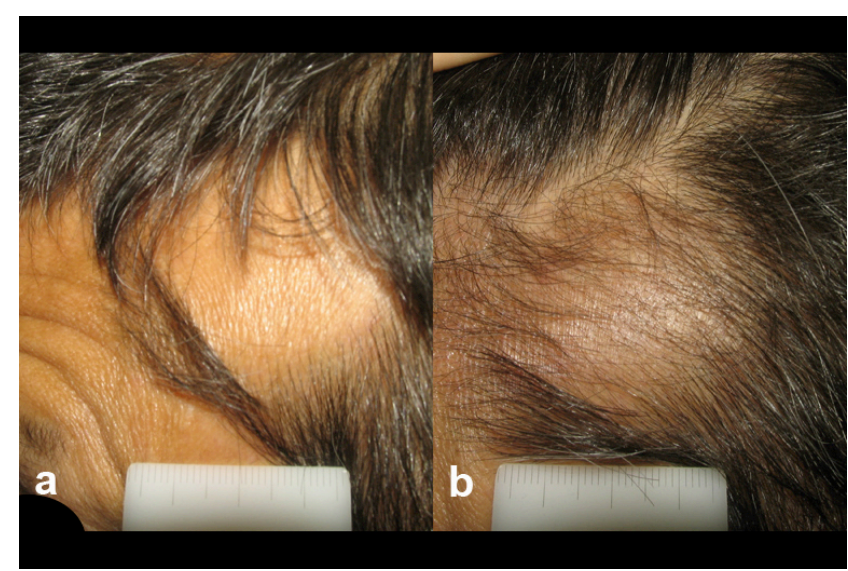

Figure 1: Patient No. 1- Temporal alopecia areata plate (a) and response after 1month of treatment with fractional laser (b).

Our group has extensive experience in laser hair removal since 1998. We were among the first groups to describe the stimulation of hair removal laser, one of the most unknown and interesting side effects of this treatment [18]. We also make our own hypothesis that stimulation of hair happens by such energies, which are not high enough to destroy the germ cells but are sufficient to stimulate the growth of short fine clear hair to thicker, long and dark. We believe it could be by increasing blood flow in the dermal papilla, secondary to thermal stimulus.

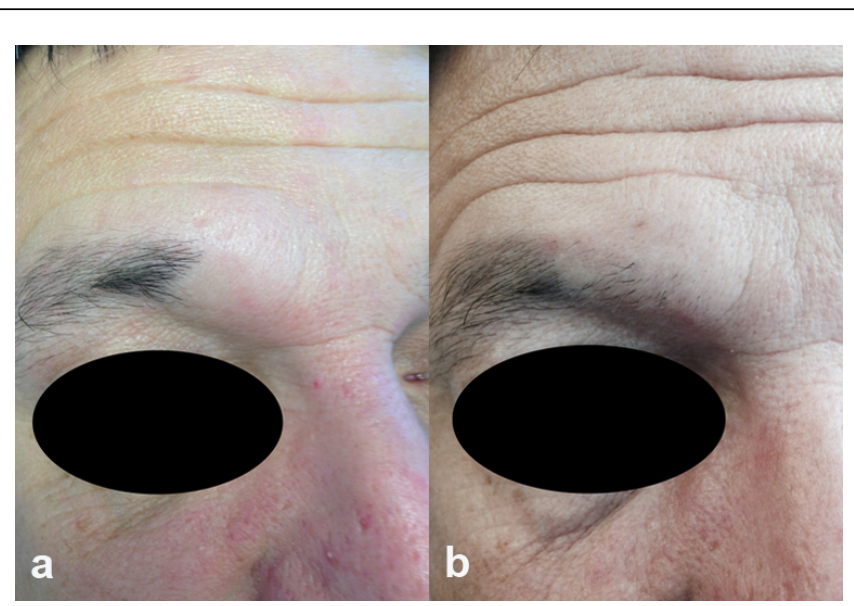

Figure 2: Patient No. 1- Alopecia areata in eyebrow head before (a) and after 1 month of treatment with fractional laser (b).

Bolstered by this hypothesis we encourage treating these patients with alopecia areata with a heating system capable of penetrating up to dermal papilla and stimulate blood flow. A laser capable of penetrating with sufficient energy to the papillae, without destroying output, can accelerate hair in alopecia areata. All of our five patients treated had 
good results that suggest that the dermal heat introduced acts as hair growth stimulant in general and in alopecia areata in particular.

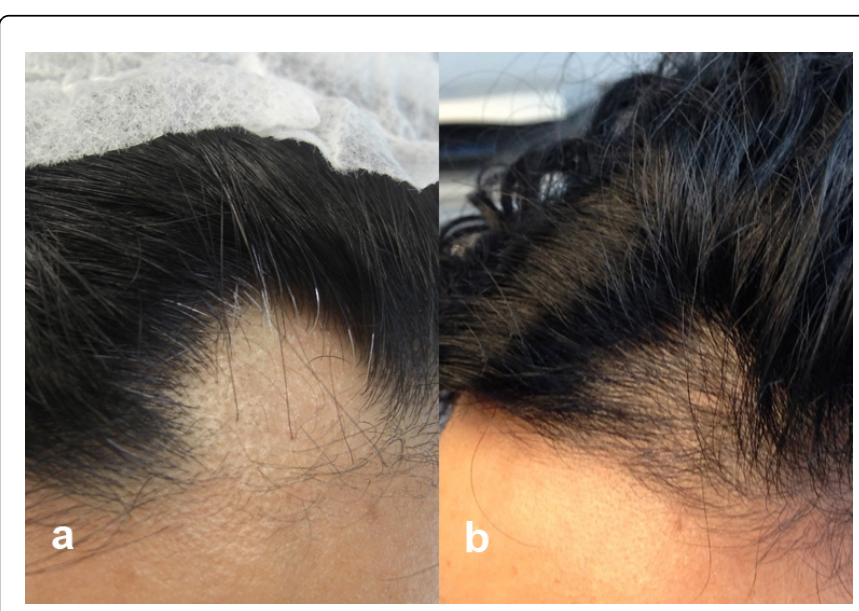

Figure 3: Patient No. 2- Frontal alopecia areata patch before (a) and after 3 months of treatment with fractional laser (b).

The high rate of spontaneous remission makes difficult to assess the efficacy, however, regrowth cannot be expected before 3 months [1]. In patient 1 , the output of hair with laser was faster than with intralesional corticosteroids. Compared with the treatments of choice, it seems that laser therapy could have a faster onset of action. In previous studies initial regrowth was seen at 3 months with topical corticosteroids, diphencyprone or minoxidil and at 4-6 weeks with intralesional or systemic corticosteroids $[5,19]$.

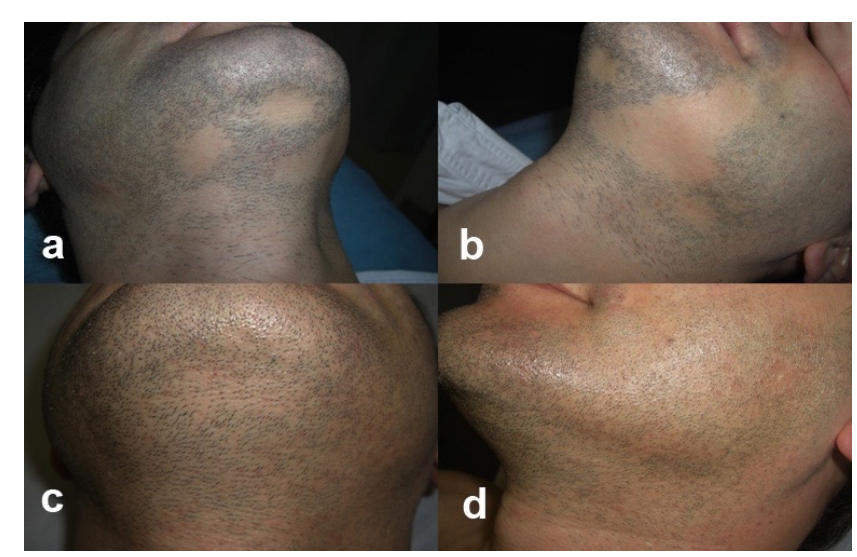

Figure 4: Patient No. 4- Beard alopecia areata $(a, b)$ in full regrowth after 3 months of treatment with fractional laser (c, d).

Similarly, it has been observed the appearance of new plaques with conventional and laser therapy, due to what it is important that the treatment can be repeated [5]. It seems that in our series hair regrowth with laser is longer and more homogeneous as with intralesional corticosteroids. It could be due to the thermal energy being distributed more homogeneously than the drug. Another advantage is that the laser can avoid skin atrophy of steroids, offer a cosmetically good response and can be repeated if needed. The disadvantages could be the pain and the price of the laser that is not reimbursable by insurance.
It could be interesting in monotherapy as in our cases or even in a combined therapy with conventional treatments that could have synergistic effect [20].

\section{Conclusion}

In conclusion, we propose that a fractional laser capable of producing heat in papillary dermis can stimulate hair output in alopecia areata, being quickly, evenly and safe. More studies are needed to confirm these results and determine optimal therapeutic parameters.

\section{References}

1. Messenger AG, McKillop J, Farrant P, McDonagh AJ, Sladden M (2012) British Association of Dermatologists guidelines for the management of alopecia areata 2012. Br J Dermatol 166: 916-926.

2. Hordinsky M, Donati A (2014) Alopecia areata: an evidence-based treatment update. Am J Clin Dermatol 15: 231-246.

3. Walker SA, Rothman S (1950) Alopecia areata: a statistical study and consideration of endocrine influences. J Invest Dermatol 14: 403-413.

4. Gip L, Lodin A, Molin L (1969) Alopecia areata. A follow-up investigation of outpatient material. Acta Derm Venereol 49: 180-188.

5. Bolduc $\mathrm{CH}$, Shapiro J (2001) The treatment of alopecia areata. Dermatol Ther 14: 306-316.

6. Rangwala S, Rashid RM (2012) Alopecia: a review of laser and light therapies. Dermatol Online J 18: 3.

7. McMichael AJ (2013) Excimer laser: a module of the alopecia areata common protocol. J Investig Dermatol Symp Proc 16:S77-S79.

8. Ohtsuki A, Hasegawa T, Komiyama E, Takagi A, Kawasaki J, et al. (2013) 308-nm Excimer Lamp for the Treatment of Alopecia Areata: Clinical Trial on 16 Cases. Indian J Dermatol 58: 326.

9. Bayramgürler D, Demirsoy EO, Aktürk AŞ, Kıran R (2011) Narrowband ultraviolet B phototherapy for alopecia areata. Photodermatol Photoimmunol Photomed 27: 325-327.

10. Waiz M, Saleh AZ, Hayani R, Jubory SO (2006) Use of the pulsed infrared diode laser $(904 \mathrm{~nm})$ in the treatment of alopecia areata. J Cosmet Laser Ther 8: 27-30.

11. Avci P, Gupta GK, Clark J, Wikonkal N, Hamblin MR (2014) Low-level laser (light) therapy (LLLT) for treatment of hair loss. Lasers Surg Med 46: 144-151.

12. Yoo KH, Kim MN, Kim BJ, Kim CW (2010) Treatment of alopecia areata with fractional photothermolysis laser. Int J Dermatol 49: 845-847.

13. Cho S, Choi MJ, Zheng Z, Goo B, Kim DY, et al. (2013) Clinical effects of non-ablative and ablative fractional lasers on various hair disorders: a case series of 17 patients. J Cosmet Laser Ther 15: 74-79.

14. Kim WS, Lee HI, Lee JW, Lim YY, Lee SJ, et al. (2011) Fractional photothermolysis laser treatment of male pattern hair loss. Dermatol Surg 37: 41-51.

15. Lee GY, Lee SJ, Kim WS (2011) The effect of a $1550 \mathrm{~nm}$ fractional erbiumglass laser in female pattern hair loss. J Eur Acad Dermatol Venereol 25: 1450-1454.

16. Manstein D, Herron GS, Sink RK, Tanner H, Anderson RR (2004) Fractional photothermolysis: a new concept for cutaneous remodeling using microscopic patterns of thermal injury. Lasers Surg Med 34: 426-438.

17. Bae JM, Jung HM, Goo B, Park YM (2015) Hair regrowth through wound healing process after ablative fractional laser treatment in a murine model. Lasers Surg. Med 47: 433-440.

18. Willey A, Torrontegui J, Azpiazu J, Landa N (2007) Hair stimulation following laser and intense pulsed light photo-epilation: review of 543 cases and ways to manage it. Lasers Surg Med 39: 297-301.

19. Tosti A, Iorizzo M, Botta GL, Milani M (2006) Efficacy and safety of a new clobetasol propionate $0.05 \%$ foam in alopecia areata: a randomized, 
Citation: Landa N, Mendieta M, Lambea R (2016) Alopecia Areata: Good Response to Treatment with Fractional Laser in 5 Cases. J Cosmo Trichol 2: 1000108. doi:10.4172/2471-9323.1000108

Page 4 of 4

double-blind placebo-controlled trial. J Eur Acad Dermatol Venereol 20: 1243-1247.
20. Issa MC, Pires M, Silveira P, Xavier de Brito E, Sasajima C (2015) Transepidermal drug delivery: a new treatment option for areata alopecia? J Cosmet Laser Ther 17: 37-40. 